\title{
Suplementação da dieta de codornas com minerais nas formas orgânicas sobre o desempenho e a qualidade dos ovos
}

\author{
[Supplementation in quail diet with organic minerals on performance and egg quality] \\ R.A. Gravena, R.H. Marques, J. Picarelli, J.D.T. Silva, J. Roccon, F.H. Hada, \\ S.A. Queiroz, V.M. B. Moraes
}

Faculdade de Ciências Agrárias e Veterinárias de Jaboticabal - UNESP

Via de Acesso Prof. Paulo Donato Castellane s/n

14884-900 - Jaboticabal, SP

\begin{abstract}
RESUMO
Foram realizados três experimentos com o objetivo de avaliar o efeito da suplementação de minerais na forma orgânica na dieta de codornas japonesas na fase de postura sobre o desempenho e a qualidade de ovos das aves. Os níveis de minerais utilizados por kg de ração, para cada experimento, foram: controle, 0,35, 0,70 e 1,05mg de Se orgânico (experimento 1); controle, 50, 100 e 150mg de Zn orgânico (experimento 2) e controle, 60, 120 e 180mg de Mn orgânico (experimento 3). As aves foram distribuídas em delineamento inteiramente ao acaso, sendo oito aves por parcela e seis repetições por tratamento. Foram avaliadas as características de desempenho - consumo diário de ração, peso dos ovos, porcentagem de postura, conversão alimentar por massa de ovos e por dúzia de ovos e viabilidade - e qualidade dos ovos - unidade Haugh, índice gema, porcentagens de casca, albúmen e gema, espessura de casca e gravidade específica. O Zn orgânico suplementado à dieta melhorou o desempenho das aves e a qualidade dos ovos, o Mn orgânico melhorou a qualidade da casca e reduziu o peso dos ovos e o Se não apresentou efeitos sobre as características avaliadas.
\end{abstract}

Palavras-chave: codorna japonesa, manganês, minerais orgânicos, selênio, zinco

\begin{abstract}
Three experiments were carried out to evaluate the effect of minerals in organic form in diet supplementation in Japanese quails performance. The levels of minerals used per $\mathrm{kg}$ of diet for each experiment were: Experiment 1: control, 0.35; 0.70 and 1.05mg organic; Experiment 2: control, 50; 100 and 150mg organic Zn; and Experiment 3: control, 60; 120 and 180mg organic Mn. The birds were randomly allotted in treatments with eight birds per experimental unit and six replicates per treatment. Performance traits of the quails estimated by daily feed intake, egg weight, egg production, feed conversion by egg mass and per dozen eggs and viability, and egg quality measured by Haugh unit, yolk index, shell, albumen and yolk percentage, shell thickness and specific gravity were evaluated. The organic Zn diet supplementation improved bird performance and egg quality, the organic Mn diet improved eggshell quality and reduced egg weight, and the Se diet did not affect the evaluated characteristics.
\end{abstract}

Keywords: Japanese quail, manganese, organic mineral, selenium, zinc

\section{INTRODUÇÃO}

Os minerais orgânicos, ao invés de utilizar as vias normais de captação de íons no intestino delgado, usadas pelos minerais inorgânicos, são capazes de utilizar vias de captação de peptídeos ou aminoácidos. Desse modo, a competição entre minerais pelo mesmo transportador é evitada.
Além disso, os minerais orgânicos são mais estáveis e protegidos bioquimicamente das reações adversas com outros nutrientes presentes na dieta, por isso apresentam maior biodisponibilidade (Close, 1998).

O selênio ( $\mathrm{Se}$ ) é essencial ao organismo animal, pois, quando as células estão adequadamente

Recebido em 15 de maio de 2010 
supridas com Se, são menos susceptíveis aos danos endógenos e exógenos causados por radicais livres que podem atacar o DNA, provocando mutações e ativação química ou viral de agentes carcinogênicos. A proteção contra danos de radicais livres no organismo é dependente do Se presente na glutationa peroxidase (GSH-Px) e outras selenoproteínas na forma de selenocisteína (Schauzer et al., 1980). Porém, a suplementação de Se orgânico na dieta de poedeiras pode resultar em alterações na qualidade dos ovos, tais como aumento da porcentagem de gema, redução na porcentagem da casca (Fernandes et al., 2008) e aumento nos valores de unidade Haugh e no peso dos ovos (Arpásová et al., 2009).

O zinco ( $\mathrm{Zn}$ ) é, também, essencial aos animais, pois participa do processo de crescimento celular e da produção de enzimas necessárias à síntese de RNA e DNA (Pfeiffer et al., 1997). Participa da atividade de, aproximadamente, 300 enzimas e desempenha diversas funções metabólicas no organismo, sendo uma dessas funções relacionada à defesa do organismo contra a ação de radicais livres (Prasad e Kucuk, 2002). Resultados apresentados na literatura são contraditórios sobre o efeito da suplementação da dieta de poedeiras com $\mathrm{Zn}$ orgânico. Tabatabaie et al. (2007) observaram melhora na conversão alimentar e na redução do consumo de ração, e Yildiz et al. (2006) relataram aumento na espessura da casca e do peso dos ovos de codornas japonesas com a suplementação deste mineral.

O manganês $(\mathrm{Mn})$ é essencial à manutenção da saúde do organismo animal, desempenhando várias funções. Está diretamente envolvido com as enzimas fosfatase óssea, fosfatase alcalina e arginase, além de participar da síntese de proteínas que estimulam a ativação da DNA e da RNA polimerases (Wiberg e Neuman, 1957) e de colaborar com o metabolismo proteico e energético, e com síntese de colesterol e de mucopolissacarídeos (Friedman et al., 1987). Leach e Gross (1983) demonstraram que a deficiência de Mn na dieta de aves resultou em ovos com cascas mais finas, com alterações ultraestruturais na camada mamilar da casca e redução no teor de hexozamina e ácido hexurônico na matriz orgânica. A comprovação de que o Mn influencia a qualidade da casca foi descrita por alguns pesquisadores que, ao suplementarem a dieta de poedeiras com $\mathrm{Mn}$, observaram aumento na espessura da casca e na gravidade específica (Fassani et al., 2000).

Sabendo-se que esses minerais podem melhorar o desempenho e a qualidade dos ovos, e que a forma orgânica é mais disponível ao animal, o presente estudo teve como objetivo avaliar o efeito da suplementação da dieta de codornas japonesas com Se, Zn e Mn nas formas orgânicas sobre estas características.

\section{MATERIAL E MÉTODOS}

Foram realizados três experimentos, em que as aves foram alojadas em galpão convencional, com gaiolas dispostas em degraus, bebedouro do tipo nipple e comedouro contínuo de chapa galvanizada, onde receberam 17 horas de luz diárias e manejo normal de criação.

As aves receberam suplementação com Se, controle, 0,35; 0,7 e 1,05mg de $\mathrm{Se} / \mathrm{kg}$ de ração no experimento 1; com Zn, controle, 50; 100 e $150 \mathrm{mg}$ de $\mathrm{Zn} / \mathrm{kg}$ de ração no experimento 2 e com Mn, controle, 60; 120 e $180 \mathrm{mg}$ de $\mathrm{Mn} / \mathrm{kg}$ de ração no experimento 3 . Todos os minerais estavam na forma orgânica. Nos experimentos 1 e 2, as aves tinham 70 dias de idade, e no experimento 344 semanas.

Em todas as dietas, incluindo as suplementadas com minerais orgânicos, foram adicionados minerais nas formas inorgânicas, presentes no suplemento mineral e vitamínico. Em todos os experimentos, as codornas receberam a mesma dieta basal (Tab. 1), variando apenas a suplementação dos minerais orgânicos, formulada com base nas exigências nutricionais propostas por Murakami et al. (1993), com qualidades de $\mathrm{Se}, \mathrm{Zn}$ e $\mathrm{Mn}$ recomendados pelo Nutrient... (1994) e composição de ingredientes recomendada por Rostagno et al. (2005).

Nas dietas basais, foram utilizadas fontes inorgânicas de Se, Zn e Mn, selenito de sódio, sulfato de zinco e sulfato de manganês, respectivamente, e nas dietas suplementadas com $\mathrm{Se}, \mathrm{Zn}$ e Mn, formas orgânicas. Foram utilizados Sel-Plex ${ }^{\circledR} \quad(0,1 \%$ de Se $), \quad$ Bioplex ${ }^{\circledR}$ Zinco $(15 \%$ de $\mathrm{Zn})$ e Bioplex® Manganês (15\% de $\mathrm{Mn}$ ), respectivamente, da empresa Alltech Agroindustrial do Brasil Ltda. 
Suplementação da dieta...

Tabela 1. Composição percentual e calculada das dietas fornecidas às aves

\begin{tabular}{|c|c|}
\hline Ingrediente & $\%$ \\
\hline Milho & 63,507 \\
\hline Farelo de soja & 27,622 \\
\hline Fosfato bicálcico & 2,602 \\
\hline Calcário & 4,864 \\
\hline Sal comum $(\mathrm{NaCl})$ & 0,400 \\
\hline Suplemento vitamínico e mineral ${ }^{1}$ & 0,500 \\
\hline L-Lisina $(78 \%)$ & 0,336 \\
\hline DL-Metionina $(98 \%)$ & 0,169 \\
\hline Total & 100 \\
\hline \multicolumn{2}{|l|}{ Composição calculada } \\
\hline Proteína bruta $(\%)$ & 18 \\
\hline Energia metabolizável (kcal/kg) & 2800 \\
\hline Cálcio $(\%)$ & 2,5 \\
\hline Fósforo disponível (\%) & 0,55 \\
\hline Lisina total $(\%)$ & 1,30 \\
\hline Metionina + Cistina total $(\%)$ & 0,76 \\
\hline Selênio $(\%)$ & 0,00003 \\
\hline Zinco $(\%)$ & 0,007 \\
\hline Manganês (\%) & 0,006 \\
\hline
\end{tabular}

A metodologia para a avaliação de desempenho e da qualidade dos ovos foi semelhante em todos os experimentos. Foram utilizadas 192 codornas na fase de postura, distribuídas em delineamento inteiramente ao acaso, com quatro tratamentos, seis repetições e oito aves por parcela. Foram realizados quatro ciclos de postura de 14 dias cada, e, ao final de cada ciclo, foram avaliadas as características de desempenho, consumo de ração, produção de ovos, peso médio dos ovos, conversão alimentar por massa e por dúzia de ovos, a viabilidade e qualidade dos ovos, unidade Haugh, índice gema, porcentagens de casca, albúmen e gema, gravidade específica e espessura da casca.

Para as análises estatísticas de desempenho e qualidade dos ovos, foram utilizados procedimentos de análises por regressão polinomial a $5 \%$ de probabilidade, sendo todas as análises realizadas no programa estatístico $\mathrm{SAS}^{\circledR}$.

\section{RESULTADOS E DISCUSSÃO}

Os resultados de desempenho das aves do experimento 1 (Tab. 2) evidenciaram que a suplementação de Se orgânico na dieta não alterou o desempenho das codornas, dessa forma, não foi necessária a utilização do produto com o objetivo de melhorar o desempenho das aves. Estes resultados de desempenho foram semelhantes aos obtidos por Chantiraticul et al. (2008) e Mohiti-asli et al. (2008), que não observaram efeito significativo sobre $o$ desempenho de galinhas poedeiras que receberam dietas suplementadas com 0,$3 ; 1,0$ e 3,0ppm de Se orgânico.

Stanley et al. (2004) observaram aumento na produção e no peso dos ovos ao suplementar a dieta das aves com Sel-Plex ${ }^{\circledR}$ (1lb/ton), e Skrivan et al. (2006) verificaram aumento no peso dos ovos das aves suplementadas com 0,3ppm de Se orgânico. Fernandes et al. (2008) forneceram dietas com 0; 250 e 500ppm de um produto composto por zinco, manganês e selênio nas formas orgânicas para poedeiras e observaram menor peso dos ovos das aves que receberam $250 \mathrm{ppm}$ do produto em relação ao tratamentocontrole, no entanto o desempenho das aves não foi afetado. 
Tabela 2. Médias de consumo diário de ração (CR), peso médio dos ovos (PO), porcentagem de postura (PP), conversão alimentar por massa de ovos (CA) e por dúzia de ovos (CD) e viabilidade (V) das codornas suplementadas com selênio orgânico

\begin{tabular}{lllllll}
$\begin{array}{l}\text { Suplementação } \\
(\mathrm{mg} \mathrm{Se} / \mathrm{kg} \text { de ração })\end{array}$ & $\begin{array}{l}\text { CR } \\
(\mathrm{g})\end{array}$ & $\begin{array}{l}\mathrm{PO} \\
(\mathrm{g})\end{array}$ & $\begin{array}{l}\mathrm{PP} \\
(\%)\end{array}$ & $\begin{array}{l}\mathrm{CA} \\
(\mathrm{kg} / \mathrm{kg})\end{array}$ & $\begin{array}{l}\mathrm{CD} \\
(\mathrm{kg} / \mathrm{dz})\end{array}$ & $\begin{array}{l}\mathrm{V} \\
(\%)\end{array}$ \\
\hline 0 & 26,26 & 11,19 & 88,56 & 2,69 & 0,357 & 98,96 \\
0,35 & 26,97 & 10,95 & 91,86 & 2,69 & 0,354 & 97,92 \\
0,7 & 26,54 & 11,04 & 89,61 & 2,69 & 0,356 & 98,96 \\
1,05 & 26,85 & 11,19 & 87,68 & 2,73 & 0,366 & 98,96 \\
\hline CV $(\%)$ & 3,98 & 1,99 & 4,42 & 4,56 & 5,19 & 1,63 \\
Valor de F & 0,49 & 0,08 & 0,33 & 0,27 & 0,68 & 0,13 \\
Probabilidade & $0,49^{\text {ns }}$ & $0,78^{\text {ns }}$ & $0,57^{\text {ns }}$ & $0,61^{\text {ns }}$ & $0,42^{\text {ns }}$ & $0,73^{\text {ns }}$ \\
\hline
\end{tabular}

ns = regressão não significativa $(\mathrm{P}>0,05)$.

A suplementação da dieta das codornas em quantidades crescentes de Se orgânico não alterou os resultados de unidade Haugh, índice gema, porcentagens de casca, gema e albúmen, espessura da casca e gravidade específica dos ovos (Tab. 3). Da mesma maneira, Chantiraticul et al. (2008) verificaram que os valores de unidade Haugh e espessura da casca de ovos de galinhas poedeiras não se alteraram quando as aves receberam dietas suplementadas com Se orgânico nas quantidades de 0;0,3; 1,0 e 3,0ppm.
Resultados encontrados na literatura demonstram contradição em relação aos efeitos da suplementação da dieta de poedeiras com Se orgânico sobre a qualidade de ovos. Skrivan et al. (2006) observaram aumento no peso de albúmen e redução no peso da gema com a suplementação de 0,3 ppm de Se orgânico na dieta, enquanto Arpásová et al. (2009) mostraram que houve aumento significativo nos valores de unidade Haugh e no peso dos ovos de aves suplementadas com 0,4ppm de Se orgânico.

Tabela 3. Médias de unidade Haugh (UH), índice gema (IG), porcentagens de casca (PC), albúmen (PA) e gema (PG), gravidade específica (GE), espessura de casca (EC) dos ovos de codornas suplementadas com selênio orgânico

\begin{tabular}{llllllll}
\hline $\begin{array}{l}\text { Suplementação } \\
(\mathrm{mg} \mathrm{Se} / \mathrm{kg} \text { de ração) }\end{array}$ & $\mathrm{UH}$ & $\mathrm{IG}$ & $\begin{array}{l}\mathrm{PC} \\
(\%)\end{array}$ & $\begin{array}{l}\text { PA } \\
(\%)\end{array}$ & $\begin{array}{l}\text { PG } \\
(\%)\end{array}$ & $\begin{array}{l}\mathrm{GE} \\
\left(\mathrm{g} / \mathrm{cm}^{3}\right)\end{array}$ & $\begin{array}{l}\text { EC } \\
(\mathrm{mm})\end{array}$ \\
\hline 0 & 88,88 & 0,47 & 7,83 & 61,77 & 30,39 & 1,071 & 0,230 \\
0,35 & 88,89 & 0,48 & 7,92 & 61,83 & 30,23 & 1,071 & 0,236 \\
0,70 & 88,66 & 0,47 & 7,89 & 61,65 & 30,46 & 1,072 & 0,232 \\
1,05 & 88,83 & 0,48 & 7,78 & 61,91 & 30,31 & 1,071 & 0,231 \\
\hline $\mathrm{CV}(\%)$ & 1,55 & 2,37 & 3,24 & 1,23 & 2,64 & 1,72 & 3,05 \\
Valor de F & 0,02 & 0,04 & 0,19 & 0,04 & 0,00 & 0,39 & 0,13 \\
Probabilidade & $0,88^{\mathrm{ns}}$ & $0,84^{\mathrm{ns}}$ & $0,67^{\mathrm{ns}}$ & $0,85^{\mathrm{ns}}$ & $0,99^{\text {ns }}$ & $0,54^{\mathrm{ns}}$ & $0,72^{\mathrm{ns}}$ \\
\hline
\end{tabular}

ns = regressão não significativa $(\mathrm{P}>0,05)$.

Os resultados de desempenho do experimento 2 (Tab. 4) mostram que a suplementação da dieta com $\mathrm{Zn}$ orgânico não influenciou $(\mathrm{P}>0,05)$ o consumo de ração, a conversão alimentar por dúzia de ovos, o peso dos ovos, porcentagem de postura e a viabilidade, no entanto a conversão alimentar por dúzia foi ligeiramente melhor $(\mathrm{P}=0,07)$ com a suplementação do mineral na dieta.

A suplementação da dieta com $\mathrm{Zn}$ orgânico melhorou linearmente a conversão alimentar por massa de ovos $\left(y=2,72812-0,00115 x, R^{2}=0,18\right)$. Isso se justifica pela tendência de redução do consumo com a suplementação de $\mathrm{Zn}$, que influenciou a conversão alimentar por massa de ovos. Estes resultados estão parcialmente de acordo com os obtidos por Tabatabaie et al. (2007), que verificaram redução no consumo de ração e melhora na conversão alimentar de poedeiras suplementadas com 50ppm de $\mathrm{Zn}$ orgânico na dieta. As outras características de desempenho não foram alteradas pela suplementação. Entretanto, o coeficiente de determinação da análise de regressão indica que o modelo para conversão alimentar explicou apenas $18 \%$ da variância. 
Tabela 4. Médias de consumo diário de ração (CR), conversão alimentar por massa de ovos (CA), conversão alimentar por dúzia de ovos (CD), peso dos ovos (PO), porcentagem de postura (PP) e viabilidade (V) de aves suplementadas com zinco orgânico

\begin{tabular}{lllllll}
$\begin{array}{l}\text { Suplementação } \\
(\mathrm{mg} \mathrm{Zn/kg} \mathrm{de} \mathrm{ração)}\end{array}$ & $\begin{array}{l}\text { CR } \\
(\mathrm{g})\end{array}$ & $\begin{array}{l}\mathrm{PO} \\
(\mathrm{g})\end{array}$ & $\begin{array}{l}\mathrm{PP} \\
(\%)\end{array}$ & $\begin{array}{l}\mathrm{CA} \\
(\mathrm{kg} / \mathrm{kg})\end{array}$ & $\begin{array}{l}\mathrm{CD} \\
(\mathrm{kg} / \mathrm{dz})\end{array}$ & $\begin{array}{l}\mathrm{V} \\
(\%)\end{array}$ \\
\hline 0 & 27,63 & 10,95 & 93,00 & 2,72 & 0,357 & 98,75 \\
50 & 26,70 & 11,14 & 91,75 & 2,67 & 0,357 & 100 \\
100 & 27,02 & 11,14 & 92,83 & 2,62 & 0,350 & 100 \\
150 & 26,55 & 11,15 & 93,45 & 2,55 & 0,341 & 99,48 \\
\hline CV $(\%)$ & 3,06 & 2,01 & 3,26 & 5,39 & 4,67 & 1,08 \\
Valor de F & 2,83 & 2,17 & 0,18 & 4,85 & 3,47 & 0,87 \\
Probabilidade & $0,06^{\text {ns }}$ & $0,15^{\text {ns }}$ & $0,67^{\text {ns }}$ & $0,04^{*}$ & 0,07 & $0,36^{\mathrm{ns}}$ \\
\hline
\end{tabular}

$\mathrm{ns}=$ regressão não significativa $(\mathrm{P}>0,05) ;{ }^{*}$ regressão linear significativa $(\mathrm{P}<0,05)$.

Swiatkiewicz e Koreleski (2008), ao suplementarem poedeiras em segundo ciclo de produção com 50 e 100ppm de Zn orgânico na dieta, observaram que o peso médio, a produção de ovos, o consumo de ração e a conversão alimentar por massa de ovos foram inalterados. Alguns resultados obtidos na literatura consultada foram contraditórios aos deste estudo. A suplementação da dieta de poedeiras com $\mathrm{Zn}$ nas formas orgânicas e inorgânicas com 30 e 60ppm, no período de 69 a 82 semanas de idade, proporcionou redução no peso dos ovos, fato este explicado pelo menor peso dos ovos das aves destes tratamentos no período anterior ao início do experimento (Mabe et al., 2003). No entanto, Paik e Lim (2003) observaram que a produção de ovos de aves suplementadas com 100ppm de $\mathrm{Zn}$ orgânico foi reduzida em relação às aves do tratamento-controle.

As características de qualidade dos ovos do experimento 2 (Tab. 5) não foram alteradas com a suplementação de $\mathrm{Zn}$ orgânico na dieta das aves, com exceção dos valores de unidade Haugh, que foram influenciados de forma quadrática $\left(\mathrm{y}=87,3274+0,02805 \mathrm{x}-0,00023017 \mathrm{x}^{2}\right.$, $\mathrm{R}^{2}=0,32$ ) pela suplementação do mineral na dieta, sendo a melhor quantidade estimada igual a $60,93 \mathrm{mg}$ de $\mathrm{Zn} / \mathrm{kg}$ da dieta. O modelo empregado para unidade Haugh explicou apenas $32 \%$ da variação dessa característica.

Tabela 5. Médias de unidade Haugh (UH), índice gema (IG), porcentagens de casca (PC), albúmen (PA) e gema (PG), gravidade específica (GE) e espessura de casca (EC) dos ovos das aves suplementadas com zinco orgânico

\begin{tabular}{llllllll}
\hline $\begin{array}{l}\text { Suplementação } \\
(\mathrm{mg} \mathrm{Zn/} \mathrm{kg} \mathrm{de} \mathrm{ração)}\end{array}$ & $\mathrm{UH}$ & $\mathrm{IG}$ & $\begin{array}{l}\text { PC } \\
(\%)\end{array}$ & $\begin{array}{l}\text { PA } \\
(\%)\end{array}$ & $\begin{array}{l}\text { PG } \\
(\%)\end{array}$ & $\begin{array}{l}\mathrm{GE} \\
\left(\mathrm{g} / \mathrm{cm}^{3}\right)\end{array}$ & $\begin{array}{l}\mathrm{EC} \\
(\mathrm{mm})\end{array}$ \\
\hline 0 & 87,17 & 0,47 & 7,77 & 61,81 & 30,42 & 1,072 & 0,237 \\
50 & 88,63 & 0,46 & 7,73 & 61,97 & 30,29 & 1,071 & 0,235 \\
100 & 87,35 & 0,47 & 7,90 & 61,60 & 30,50 & 1,072 & 0,241 \\
150 & 86,52 & 0,46 & 7,87 & 61,74 & 30,39 & 1,072 & 0,242 \\
\hline CV(\%) & 1,20 & 2,20 & 1,95 & 0,91 & 1,85 & 1,61 & 2,48 \\
Valor de F & 5,04 & 1,59 & 2,87 & 0,35 & 0,02 & 0,81 & 3,39 \\
Probabilidade & $0,01^{*}$ & $0,51^{\text {ns }}$ & $0,10^{\text {ns }}$ & $0,55^{\text {ns }}$ & $0,89^{\text {ns }}$ & $0,38^{\text {ns }}$ & $0,08^{\text {ns }}$ \\
\hline
\end{tabular}

ns = regressão não significativa $(\mathrm{P}>0,05) ; *$ regressão quadrática significativa $(\mathrm{P}<0,05)$.

Resultados semelhantes ao do presente estudo foram reportados por Tabatabaei et al. (2007), que verificaram que os valores de unidade Haugh de ovos de poedeiras suplementadas com 50ppm de $\mathrm{Zn}$ orgânico na dieta foram melhores do que o tratamento sem suplementação, sendo as outras características de qualidade dos ovos não afetadas. Entretanto, Paik e Lim (2003) não observaram efeitos benéficos da suplementação da dieta de poedeiras com 100ppm de $\mathrm{Zn}$ orgânico sobre a unidade Haugh e sobre outras características da qualidade dos ovos.

Em relação à qualidade da casca dos ovos, Swiatkiewicz e Koreleski (2008) não observaram alterações na porcentagem e espessura da casca dos ovos com 50 e 100ppm de Zn orgânico na dieta, e Dale e Strong (1998) verificaram que a 
gravidade específica dos ovos não foi alterada com a suplementação da dieta das aves com Zn e Mn orgânicos. Contudo, Mabe et al. (2003) verificaram que poedeiras produziram ovos com menor porcentagem de casca quando submetidas à suplementação de 30 e 60ppm de Zn orgânico na dieta no período de 32 a 45 semanas de idade, porém não foram observadas diferenças significativas no período de 60 a 82 semanas de idade.

Yildiz et al. (2006) verificaram que a suplementação da dieta de codornas japonesas em postura com 60ppm de $\mathrm{Zn}$ orgânico proporcionou melhora na qualidade dos ovos em função do aumento da espessura da casca, bem como melhora no índice gema e aumento do peso dos ovos. Zamani et al. (2005) avaliaram o efeito da adição de Zn inorgânico sobre a qualidade da casca dos ovos e verificaram que a suplementação com 50 e 150 ppm de $\mathrm{Zn}$ aumentou o peso dos ovos, a espessura da casca e a concentração de cálcio na casca.

Os resultados de desempenho do experimento 3 mostraram que as características de desempenho avaliadas não foram influenciadas $(\mathrm{P}>0,05)$ pela quantidade de Mn orgânico suplementado (Tab. 6). A suplementação com $\mathrm{Mn}$ influenciou de forma quadrática o peso dos ovos ( $\mathrm{Y}=11,6736$ $\left.0,0077 x+0,00004088 x^{2}, R^{2}=0,29\right)$. A quantidade de $94,17 \mathrm{mg}$ de $\mathrm{Mn}$ orgânico/kg de ração foi a que resultou em menor peso dos ovos, e o resultado de $180 \mathrm{mg}$ de $\mathrm{Mn}$ orgânico/kg de ração foi semelhante ao resultado do tratamentocontrole. O coeficiente de determinação da regressão do peso dos ovos explicou apenas $29 \%$ da variação. Uma hipótese para justificar o menor peso dos ovos na quantidade citada pode estar associada à competição com aminoácidos por sítios de absorção nos intestinos, que resultou em diminuição do peso dos ovos.

Tabela 6. Médias de consumo diário de ração (CR), porcentagem de postura (PP), peso dos ovos (PO), conversão alimentar por massa de ovos (CA), conversão alimentar por dúzia de ovos (CD) e viabilidade. (V) de aves suplementadas com manganês orgânico

\begin{tabular}{lllllll}
\hline $\begin{array}{l}\text { Suplementação } \\
(\mathrm{mg} \mathrm{Mn} / \mathrm{kg} \text { de ração })\end{array}$ & $\begin{array}{l}\mathrm{CR} \\
(\mathrm{g})\end{array}$ & $\begin{array}{l}\mathrm{PO} \\
(\mathrm{g})\end{array}$ & $\begin{array}{l}\mathrm{PP} \\
(\%)\end{array}$ & $\begin{array}{l}\mathrm{CA} \\
(\mathrm{kg} / \mathrm{kg})\end{array}$ & $\begin{array}{l}\mathrm{CD} \\
(\mathrm{kg} / \mathrm{dz})\end{array}$ & $\begin{array}{l}\mathrm{V} \\
(\%)\end{array}$ \\
\hline 0 & 28,60 & 11,66 & 86,73 & 2,84 & 0,397 & 99,48 \\
60 & 28,21 & 11,40 & 92,37 & 2,71 & 0,377 & 99,48 \\
120 & 28,45 & 11,29 & 90,39 & 2,72 & 0,376 & 99,44 \\
180 & 28,25 & 11,62 & 91,41 & 2,82 & 0,369 & 99,48 \\
\hline CV $(\%)$ & 1,67 & 2,17 & 3,96 & 7,12 & 5,94 & 1,42 \\
Valor de F & 0,88 & 4,08 & 3,90 & 0,02 & 3,70 & 0,16 \\
Probabilidade & $0,36^{\text {ns }}$ & $0,03^{*}$ & $0,07^{\text {ns }}$ & $0,89^{\text {ns }}$ & $0,07^{\text {ns }}$ & $0,69^{\text {ns }}$ \\
\hline
\end{tabular}

$\mathrm{ns}=$ regressão não significativa $(\mathrm{P}>0,05) ;$ * regressão quadrática $(\mathrm{P}<0,05)$.

Paik e Lim (2003) e Swiatkiewicz e Koreleski (2008) verificaram que a suplementação da dieta de poedeiras com até 100ppm de Mn orgânico não influenciou o desempenho das aves. Diferentes linhagens de galinhas poedeiras suplementadas com dietas com quantidades crescentes de Mn inorgânico $(0,20,40,60$ e $80 \mathrm{ppm})$ não apresentaram alterações no desempenho (Sazzad et al., 1994). No entanto, Fassani et al. (2000) observaram em poedeiras em segundo ciclo de produção que a suplementação com Mn inorgânico (0, 40, 80, 120,160 e 200ppm) reduziu a produção de ovos e aumentou o peso dos ovos, linearmente.

Os resultados de qualidade dos ovos do experimento 3, apresentados na Tab. 7, demonstram que a suplementação da dieta das aves com Mn orgânico influenciou a qualidade da casca dos ovos, pois observou-se efeito linear positivo dos tratamentos para porcentagem de casca $\quad\left(y=7,58298+0,00127 x, \quad R^{2}=0,22\right) \quad e$ espessura de casca $(\mathrm{y}=0,24071+0,00004447 \mathrm{x}$, $\mathrm{R}^{2}=0,16$ ), mas os valores de $\mathrm{R}^{2}$ não podem ser considerados altos, isto é, os modelos de regressão explicaram pouco das variações ocorridas na porcentagem e na espessura da casca. $\mathrm{O}$ fato de o $\mathrm{Mn}$ influenciar na qualidade da casca pode ter, como hipótese, a participação do Mn como cofator de metaloezimas responsáveis pela síntese de carbonatos e mucopolissacarídeos presentes na casca do ovo. No entanto, no presente estudo, essas características não foram avaliadas. 
As variáveis índice gema, unidade Haugh e as porcentagens de gema e albúmem não foram influenciadas significativamente $(\mathrm{P}>0,05)$ pela adição de Mn orgânico na dieta. Contrariando alguns resultados obtidos no presente estudo, Mabe et al. (2003), ao suplementarem a dieta de poedeiras com 30 e 60ppm de Mn orgânico, observaram redução no peso dos ovos e na porcentagem de casca dos ovos. Swiatkiewicz e
Koreleski (2008) notaram que a porcentagem e a espessura da casca dos ovos não foram alteradas com a suplementação da dieta de poedeiras com 50 e 100ppm de Mn orgânico. A qualidade da casca de ovos de poedeiras em final de postura, avaliada pelo método da gravidade específica, não foi alterada com a suplementação da dieta das aves com Mn e Zn orgânicos (Dale e Strong, 1998).

Tabela 7. Médias de unidade Haugh (UH), índice gema (IG), porcentagens de casca (PC), albúmem (PA) e gema (PG), gravidade específica (GE), espessura de casca (EC) dos ovos das aves suplementadas com manganês orgânico

\begin{tabular}{llllllll}
\hline $\begin{array}{l}\text { Suplementação } \\
(\mathrm{mg} \mathrm{Mn} / \mathrm{kg} \text { de ração) }\end{array}$ & $\mathrm{UH}$ & $\mathrm{IG}$ & $\begin{array}{l}\text { PC } \\
(\%)\end{array}$ & $\begin{array}{l}\text { PA } \\
(\%)\end{array}$ & $\begin{array}{l}\text { PG } \\
(\%)\end{array}$ & $\begin{array}{l}\mathrm{GE} \\
\left(\mathrm{g} / \mathrm{cm}^{3}\right)\end{array}$ & $\begin{array}{l}\mathrm{EC} \\
(\mathrm{mm})\end{array}$ \\
\hline 0 & 89,18 & 0,48 & 7,59 & 61,78 & 30,66 & 1,065 & 0,241 \\
60 & 90,30 & 0,48 & 7,63 & 61,30 & 31,07 & 1,067 & 0,244 \\
120 & 89,35 & 0,48 & 7,78 & 61,07 & 31,25 & 1,067 & 0,243 \\
180 & 88,74 & 0,48 & 7,80 & 61,14 & 31,10 & 1,067 & 0,250 \\
\hline $\mathrm{CV}(\%)$ & 1,45 & 1,75 & 2,19 & 1,29 & 2,57 & 0,15 & 2,88 \\
Valor de F & 0,71 & 0,19 & 6,07 & 2,22 & 1,06 & 2,38 & 4,29 \\
Probabilidade & $0,41^{\text {ns }}$ & $0,67^{\text {ns }}$ & $0,02^{*}$ & $0,15^{\text {ns }}$ & $0,31^{\text {ns }}$ & $0,13^{\text {ns }}$ & $0,05^{*}$ \\
\hline
\end{tabular}

$\mathrm{ns}=$ regressão não significativa $(\mathrm{P}>0,05) ;$ *regressão linear $(\mathrm{P}<0,05)$.

Fassani et al. (2000) observaram que a suplementação da dieta de poedeiras em segundo ciclo de postura com 0, 40, 80, 120, 160 e 200ppm Mn inorgânico não melhorou os valores de unidade Haugh, mas aumentou a espessura da casca e a gravidade específica dos ovos linearmente com o aumento de Mn na dieta. A porcentagem de casca dos ovos foi aumentada com suplementação de 60ppm de Mn inorgânico na dieta, no entanto o peso e a espessura da casca dos ovos não foram alterados (Zamani et al., 2005).

Diferentes linhagens de galinhas poedeiras foram suplementadas com dietas contendo 0, 20, 40, 60 e $80 \mathrm{ppm}$ de $\mathrm{Mn}$ na forma inorgânica, e foi observado que a suplementação foi capaz de melhorar a qualidade da casca dos ovos devido ao aumento na espessura das cascas das duas linhagens (Sazzad et al., 1994). A qualidade de ovos de poedeiras manteve-se inalterada ao receberem suplementação contendo $100 \mathrm{ppm}$ de Mn orgânico na dieta (Paik e Lim 2003).

\section{CONCLUSÕES}

Pode-se concluir que a adição de 50 e $150 \mathrm{mg}$ de Zn orgânico/kg de ração é eficiente em melhorar a qualidade dos ovos e o desempenho das aves, respectivamente, e que a suplementação com $\mathrm{Mn}$ orgânico, $180 \mathrm{mg} / \mathrm{kg}$ de ração, melhora a qualidade da casca dos ovos, pois a suplementação com Se orgânico não influencia as características avaliadas.

\section{AGRADECIMENTOS}

À Fundação de Amparo a Pesquisa do Estado de São Paulo, pelo auxílio financeiro e bolsas de mestrado, ao Sr. Osvaldo Esperança Rocha, da empresa VICAMI, pela doação das codornas utilizadas no experimento, e à Alltech® do Brasil.

\section{REFERÊNCIAS BIBLIOGRÁFICAS}

ARPÁSOVÁ, H; PETROVIC, V.; MELLEN, M. et al. The effects of supplementing sodium selenite and selenized yeast to the diet for laying hens on the quality and mineral content of eggs. J. Anim. Feed Sci., v.18, p.90-100, 2009.

CHANTIRATICUL, A.; CHINRASRI, O.; CHANTIRATIKUL, P. Effect of sodium selenite and zinc-L-selenomethionine on performance and selenium concentrations in eggs of laying hens. AsianAust. J. Anim. Sci., v.21, p.1048, 2008.

CLOSE, W.H. The role of trace mineral proteinates in pig nutrition. In: ALLTECH'S ANNUAL SYMPOSIUM, 14., 1998, Nottingham. Anais... Nottingham: Alltech, 1998. p.469-376. 
DALE, N.; STRONG, C.F. Inability to demonstrate an effect of eggshell\#49 on shell quality in older laying hens. J. Appl. Poult. Res., v.7, p.219-224, 1998.

FASSANI, E.J.; BERTECHINI, A.G.; OLIVEIRA, B.L. et al. Manganês na nutrição de poedeiras no segundo ciclo de produção. Cienc. Agrotec., v.24, p.468-478, 2000.

FERNANDES, J.I.M.; MURAKAMI, A.E. SAKAMOTO, M.I. et al. Effects of organic mineral dietary supplementation on production performance and egg quality of white layers. Braz. J. Poult. Sci., v.10, p.59-65, 2008.

FRIEDMAN, B.J.; FREELAND-GRAVES, J.H.; BALES, C.H. et al. Manganese balance and clinical observations in young men fed a manganese-deficient diet. J. Nutr., v.117, p.133-143, 1987.

LEACH Jr., R.M.; GROSS, J.R. The effect of manganese deficiency upon the ultrastructure of the eggshell. Poult. Sci., v.62, p.499-504, 1983.

MABE, I.; RAPP, C.; BRAIN, M.M. et al. Supplementation of a corn-soybean diet of manganese, copper, and zinc form organic and inorganic sources improves eggshell quality in aged laying hens. Poult. Sci., v.82, p.1903-1913, 2003.

MOHITI-ASLI, M.; SHARIATMADARI, F.; LOTFOLLAHIAN, H. et al. Effects of supplementing layer hen diets with selenium and vitamin E on egg quality, lipid oxidation and fatty acid composition during storage. Can. J. Anim. Sci., v.88, p.475-483, 2008.

MURAKAMI, A.E.; MORAES, V.M.B.; ARIKI, J. et $a l$. Níveis de proteína e energia em rações para codornas (Coturnix coturnix japonica) em postura. Rev. Bras. Zootec., v.22, p.541-551, 1993.

NUTRIENT requirements of poultry. 9. ed. Washington: National Academy, 1994. 155p.

PAIK I.K.; LIM, H.S. Effects of supplementary mineral methionine chelates $(\mathrm{Zn}, \mathrm{Cu}, \mathrm{Mn})$ on the performance and eggshell quality of laying hens. Asian-Aust. J. Anim. Sci., v.16, p.1804-1808, 2003.

PFEIFFER, C.C.; BRAVERMAN, E.R. Zinc, the brain, and behavior. Biol. Psychol., v.17, p.513-30, 1997.
PRASAD, A.S.; KUCUK, O. Zinc in cancer prevention. Canc. Metastasis Rev., v.21, p.291-295, 2002.

ROSTAGNO, H.S.; ALBINO, L.F.T.; DONZELE, J.L. et al. Tabelas brasileiras para aves e suínos: composição de alimentos e exigências nutricionais. 2.ed. Viçosa: UFV, 2005. 186p.

SAZZAD, H.M.; BERTECHINI, A.G.; NOBRE, P.T.C. Egg production, tissue deposition and mineral metabolism in two strains of commercial layers with various level of manganese in diet. Anim. Feed Sci. Technol., v.46, p.271-275, 1994.

SCHRAUZER, G.N.; McGUINNESS, J.E.; KUEHN, $\mathrm{K}$. Effects of temporary selenium supplementation on the genesis of mammary tumors in female inbred C3H/St mice. Carcinogenesis, v.1, p.199, 1980.

SKRIVAN, M.; SIMÁNE, J.; DLOUHÁ, G. et al. Effect of dietary sodium selenite, Se-enriched yeast and Se-enriched Chlorella on egg Se concentration, physical parameters of eggs and laying hens production. Czech J. Anim. Sci., v.51, p.163-167, 2006.

STANLEY, V.G.; KRUEGER, W.F.; SEFTON, A.E. Single and combined effects of yeast cell wall residue and Sel-Plex on production and egg quality of laying hens. Poult. Sci., v.83, suppl.1, p.260, 2004.

SWIATKIEWICZ, S.; KORELESKI, J. The effect of zinc and manganese source in the diet for laying hens on eggshell and bones quality. Vet. Med-Czech, v.53, p.555-563, 2008.

TABATABAEI, M.M.; ALIARABI, H.; SAKI, A.A. et al. Effect of different sources and levels of zinc on egg quality and laying hens performance. Pak. J. Biol. Sci., v.10, p.3476-3478, 2007.

YILDIZ, N.; ERISIR, Z.; SAHIM, K. et al. Effect of zinc picolinate on the quality of Japanese quail eggs. $J$. Anim. Vet. Adv., v.5, p.1181-1184, 2006.

WIBERG, J.S.; NEUMAN, W.F. The binding of bivalent metals by deoxyribonucleic and ribonucleic acids. Arch. Biochem. Bio., v.72, p.66, 1957.

ZAMANI, A.; RAMAHNI, H.R.; POURREZA, J. Supplementation of a corn-soybean meal diet with manganese and zinc improve eggshell quality in laying hens. Pak. J. Biol. Sci., v.8, p.1311-1317, 2005. 